Article

\title{
Product Segmentation and Sustainability in Customized Assembly with Respect to the Basic Elements of Industry 4.0
}

\author{
Branislav Micieta, Vladimira Binasova * , Radovan Lieskovsky, Martin Krajcovic \\ and Luboslav Dulina \\ Faculty of Mechanical Engineering, Department of Industrial Engineering, University of Zilina, \\ Univerzitná 8215/1, 01026 Žilina, Slovakia; branislav.micieta@fstroj.uniza.sk (B.M.); rado.lies@gmail.com (R.L.); \\ martin.krajcovic@fstroj.uniza.sk (M.K.); luboslav.dulina@fstroj.uniza.sk (L.D.) \\ * Correspondence: vladimira.binasova@fstroj.uniza.sk; Tel.: +421-041-513-2727
}

Received: 8 July 2019; Accepted: 17 October 2019; Published: 31 October 2019

\begin{abstract}
Sustainable manufacturing is not just about manufacturing, but also products and services. In the area of custom production processes, there may also be circumstances of organizational management where compliance with labor productivity and the due-date principle is problematic. Similar products with different operating times cause the throughput of assembly lines to slow down, increase number of works in progress (WIP), and increase productivity waste. It is possible to reduce this impact through various productivity-enhancing methods and innovations. This paper presents an innovative approach to product segmentation in the assembly phase of custom manufacturing, and a proposal for a new segmentation procedure that will allow significantly better integration of products into existing assembly processes without negatively impacting the company's production indicators. The scientific problem was defined on the basis that extending existing segmentation by the third dimension of operating times allows products in MTO (made to order) environments to be divided into families with approximately equal operating times. This will increase assembly efficiency in existing medium to large companies without large investments in the development and adaptation of assembly process products. The contributions of this work relate mainly to simple adaptations to existing processes in medium-sized businesses. The proposed solution respects the basic elements of Industry 4.0.
\end{abstract}

Keywords: product segmentation; sustainable manufacturing; adaptive assembly; operating times

\section{Introduction}

It is important to be able to adjust quickly to new production requirements and turbulent states, which may be internal or external. The aim of a manufacturing system is to maintain competitiveness in the market through the production of low-cost, high-quality products in sufficient quantities to meet customer demand. It is necessary that future generations of manufacturing companies be able to autonomously react to changes. Due to the development of new product platforms, it is necessary to ensure mutual cooperation with partner companies to provide the necessary knowledge to develop new products and solutions on the basis of shared experience. At the same time, the intention is the development of advanced materials and a new analytical approach. Simultaneously, the customer must specify requirements through the relevant communication interface and draft products must display:

- Implementation of unique information technology;

- Reliable modeling, monitoring, and simulation of manufacturing processes; 
- Reliable detection of abnormalities;

- The sustainability of production;

- Fast reconfiguration depending on the external environment.

Enterprises need an integrated telecommunications and information technology network through which they can transmit necessary information and dates within the organization. Customers may require specific and innovative products, which can have adverse effects on the environment.

A company might assemble its products in a serial assembly, or, according to high-variant and low-order types, in one batch. In all cases, the business must perform its processes efficiently, be cost-effective at a low level, and add value to the customer to make a profit $[1,2]$.

Custom assembly is one of several types of manufacturing processes that form the basis of enterprise manufacturing systems. In the area of custom assembly processes, there may also be circumstances of organizational management in which compliance with labor productivity is problematic. There are a number of productivity-enhancing methods that, together with innovations, can significantly support the development of new concepts by companies. This study does not deal with these methods, but outlines how this development can be supported using an extended segmentation method.

The scientific problem was defined on the basis that extending existing segmentation by the third dimension of operating times allows products in MTO (made to order) environments to be divided into families with approximately equal operating times, thus preventing:

- $\quad$ Slowing down of the throughput of an assembly line;

- Increased rate of works in progress (WIP) [3];

- Poor problem planning and use of assembly capabilities;

- Decrease in labor productivity.

It is important for companies to primarily understand the features and content of Industry 4.0 in order to make the transformation from machine-dominant manufacturing to digital manufacturing. In order to achieve a successful transformation, they should clearly review their positions and potential against the basic requirements set forward as Industry 4.0 standards [4].

One of the basic goals for achieving Industry 4.0 is efficient management, because future plants will have larger and more complex systems that will need to be managed efficiently. Appropriate plans should be made and an explanatory model should be developed to optimize management.

Oztemel [4], Scheer [5], and Scheuermann et al. [6] have prepared literature reviews of Industry 4.0 and related technologies. The agile factory prototype applies agile software engineering techniques to the domain of manufacturing. It explores the impact and feasibility of customer changes during assembly, using a commercially available software framework.

This paper is structured into six main sections, in which concepts related to the development of sustainable segmentation in production and assembly lines are detailed, because segmentation is fostered by the search for minimization. In Section 2, a literature survey is presented, supporting the requirements of Industry 4.0 and Machinery 4.0 from a financial, technical, and personnel point of view. In Section 3, a detailed explanation of the problem is given. In Section 4, our method for the segmentation of production systems and the required tools are described. Section 5 reports on the study of segmentation of a product line in a manufacturing enterprise. Finally, a short summary and an outlook are given in the conclusion (Section 6).

\section{Literature Survey}

Abdi and Labib [7] proposed an algorithm for grouping products for a reconfigurable manufacturing system (RMS) based on their operational similarities using the Jaccard similarity coefficient [8], a commonly used similarity coefficient for part-cell formation in cellular manufacturing.

Galan et al. [9] based their method on five similarity coefficients: modularity, commonality, compatibility, reusability, and demand. An analytic hierarchy process (AHP) was used as a weighting 
method to aggregate the five similarity coefficients into one single coefficient. Average linkage hierarchical clustering [10] is then used to cluster the products into a binary rooted tree, known as a dendrogram.

Goyal et al. [11] proposed a similarity coefficient based on operations sequence and employed it, solely, to cluster products using average linkage hierarchical clustering. Considering alternative process plans, Rakesh et al. [12] proposed a modified average linkage clustering algorithm based on the Jaccard similarity coefficient.

Industry 4.0 has been becoming a top priority for companies seeking for a possible way towards their future. Nowadays, robotics and automation are rapidly progressing due to innovations in sensors, devices, unmanned air vehicles (UAVs), information networks, optimization, and machine learning.

The IMS2020 research actions, which cluster research topics, frame the future technology development within three important aspects of manufacturing (Figure 1).

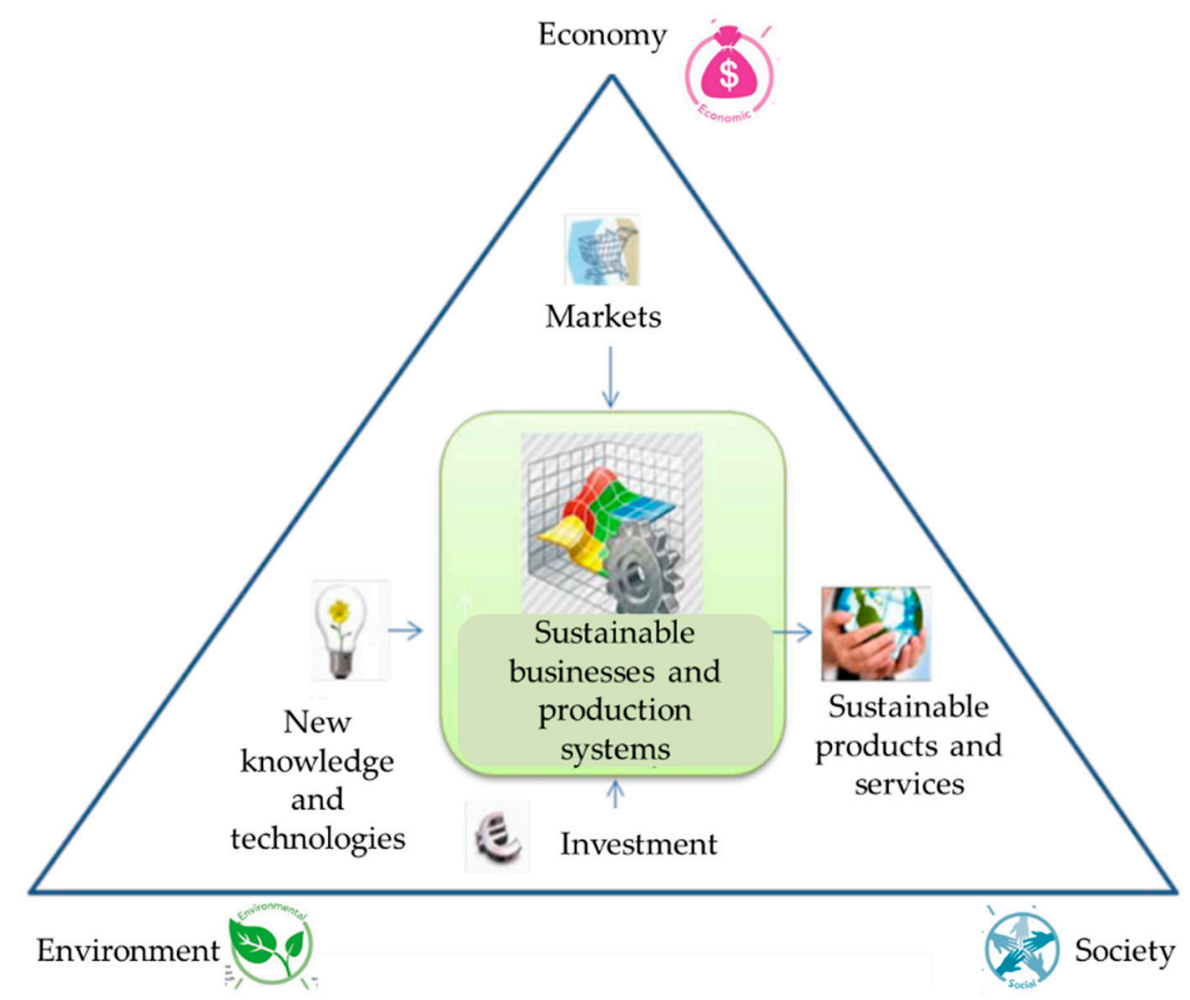

Figure 1. Sustainability and Research Model.

IMS2020 is conducted under the international, industry-led IMS (Intelligent Manufacturing Systems) Initiative established to develop the next generation of manufacturing and processing technologies, and is partly aimed at supporting global European-centric research.

The assembly industry is experiencing huge changes with the rapid development of production automation, process control, information technologies and networking. Many manufacturing and assembly enablers emerged to manage the proliferation of product variety and changes in their manufacturing systems $[13,14]$.

At present, with the changing conditions of digitizing processes and intelligent systems, the requirements of Industry 4.0 and Machinery 4.0 [15] in terms of financial, technical and personnel basis, all enterprises are seeking added values and cost reduction. Custom assembly is one of several types of manufacturing processes that are the basis of enterprise manufacturing systems [16].

There are a number of work productivity-enhancing methods that, together with innovations, significantly support development concepts by companies $[17,18]$. 
In the area of assembling processes in custom production, there may also be circumstances of organizational management where compliance with labor productivity is problematic. There is a difference when an enterprise assembles its products on a serial production line or as high variant and limited-order types in one batch. In all cases, the business must perform its processes efficiently, cost-effectively at a low level, and add value to the customer to make a profit [19-21].

The main purpose of the design concept of sustainable production is to achieve economic growth of the company, produce environmentally friendly products, meet different user requirements, use advanced technologies and increase productivity in the manufacturing and non-manufacturing processes.

In terms of sustainable production impact on selected aspects within and outside the enterprise, technologies, users, environment, economics, productivity are the most discussed [22].

Figure 2 summarizes application scenarios of different assembly systems. The application domains can be segmented in terms of the demand for changes and automation. The assembly processes with complicated changes have to be accomplished by a manual assembly since current manufacturing technologies are not intelligent enough to deal with complicated processes and a human being is the most flexible resource ever known.

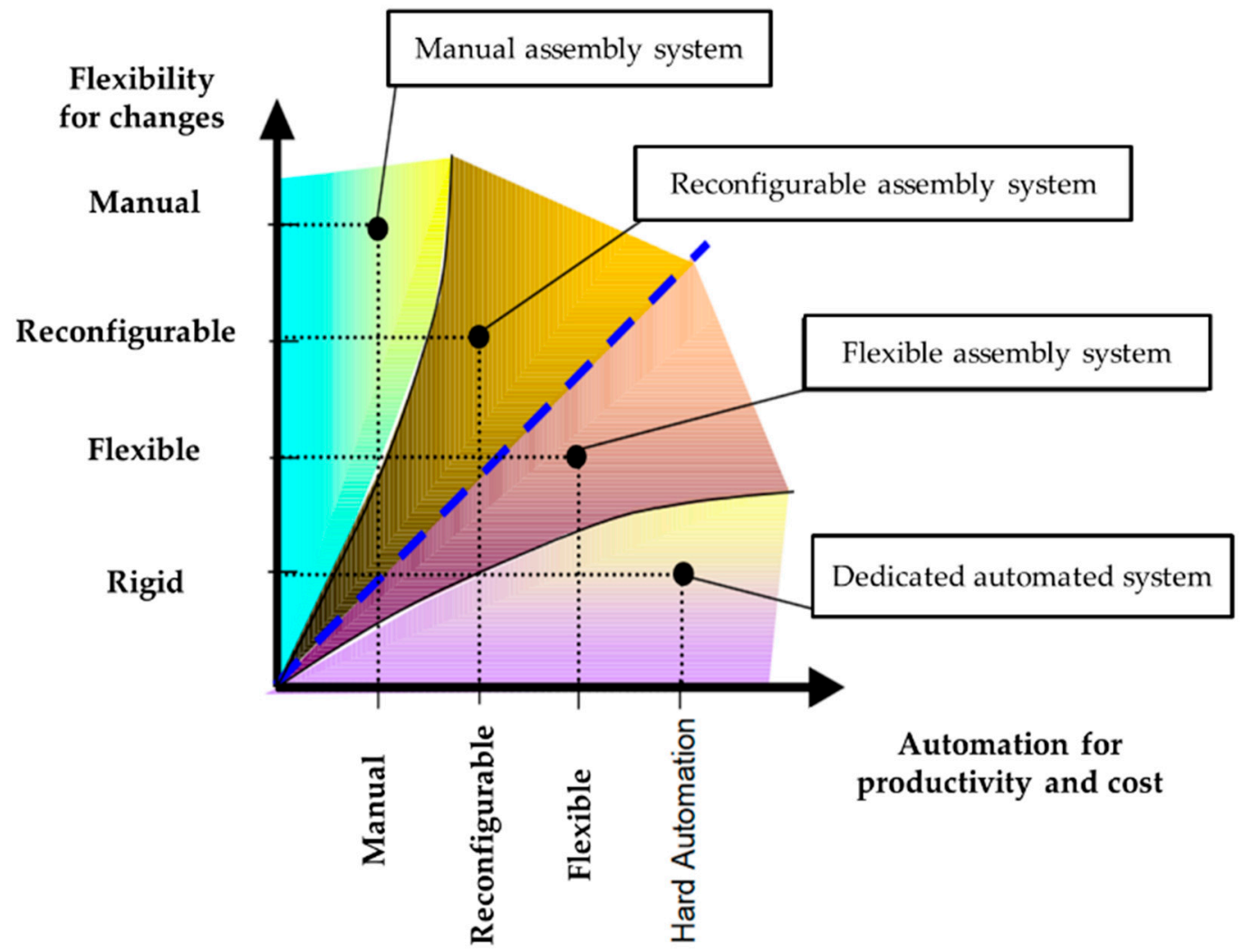

Figure 2. Scenarios of different sustainable assembly systems.

Increasing product requirements, product quality and functionality, increased labor productivity, and demands on the flexibility of the production system [23]. The product assortment is rapidly changing, the time for innovation is reduced, the demands on the reliability of the production system are increased. Therefore, it is necessary to take an innovative approach to design production and assembly systems working on the basis of high flexibility and elasticity [24,25].

The assembly is most often organized according to the workshop principle which lays the basis for the planning tasks [26-28]: layout of assembly at common facilities or production lines, product layout (depending on when certain types are to be produced), layout of workers at individual operations taking into consideration changes of workplaces after the assembly process, uneven time consumption 
by individual products, optimization of the order of the manufactured types according to the assembly lines and the occupation of the workers.

Depending on the degree of differentiation of the final product according to the customer's wishes, the production under the customer's order can be further specified depending on whether it is designed to provide a completely new product or whether the company offers a basic type of product $[29,30]$ (e.g., basic air conditioning) which is then adjusted to the customer's wishes, power or power consumption). The project solution is based on the elaborated theoretical knowledge and comprehensive analysis of the current state of affairs with regard to the problem of product segmentation before the assembly process. Its aim is to propose such an approach that would enable the product to be assembled without the use of complex planning methods. The term innovation $[31,32]$ means the result of the process of creating new things (new object).

The aim ofthe study is to find out whether existing product segmentation methods (vertical and horizontal segmentation) can be simply extended by the third dimension, such as the difference in operating times. It will help increase the throughput of the assembly line, decrease WIP and increase productivity.

The main objective of this case study is to develop a new approach to segmentation of custom assembly products based on the extension of existing segments access methods, allowing to respect the duration of assembly operations. The approach provides on the one hand support for the planning of orders in existing assembly lines and on the other hand it provides the basis for the future design of production systems, whether traditional or digital. The purpose of the case study is to extend the knowledge base that serves to design and improve production systems.

The current performance of the manufacturing systems determines a clear definition of system boundaries $[33,34]$.

\section{Problem Definition}

The main scientific objective of this case study is based on the scientific research the aims of which is to design the innovative approach to products segmentation in the assembly processes in customized production based on the requirements of the fourth industrial revolution. The proposed model of segmentation products will enable us to achieve the desired added value by optimizing operating cost of production. The development of sophisticated information technology and intelligent control of business processes is the key to the humanization of human labor. The trend is projected to accelerate depending on the production environment. In production, it is necessary to use information technology with the support of digital engineering (control systems), modelling and monitoring systems. In view of turbulent external environments, it requires a high complexity of supply chain management, which affects the development of software platforms for enterprise resource planning, management of finances and time efficiency of contract performance.

The turbulent market and global competition affect the requirement for shorting innovation cycle. As a result, aspects and complexities of inter-network cooperation cause the growing number of enterprise tasks. Disposition of product models allows for the simultaneous realization of product development and manufacturing, thus reducing the time needed to produce the required dose and perform simulation procedures.

Advanced segmentation can split products in the MTO environment to product families that have common features and approximately the same operating times and thus increase the seriality of the already existing assembly process in medium and large-sized companies without the need for big investment in the field of development and adaptation of products to the assembly process.

Artificial intelligence should be integrated into the enterprise' system in order to ensure autonomous tasks directly through the agent communication. Individual agents can transmit tasks and in the frame of interactive activities conduct evaluation activities.

Mutual communication is based on priority rules for the realization of the current transformational needs of the defined roles in meeting the corporate goals. To build adaptable manufacturing enterprise 
with embedded intelligence a key technology is needed. This technology can be obtained through the establishment of transparent agent's infrastructure.

The mechanism (Figure 3) is designed to educate the manufacturing facility in terms of autonomous operation. The emphasis is placed on acquiring knowledge from the external and internal environment, which is necessary for optimization of the product design, manufacturing processes, operations and production plan.

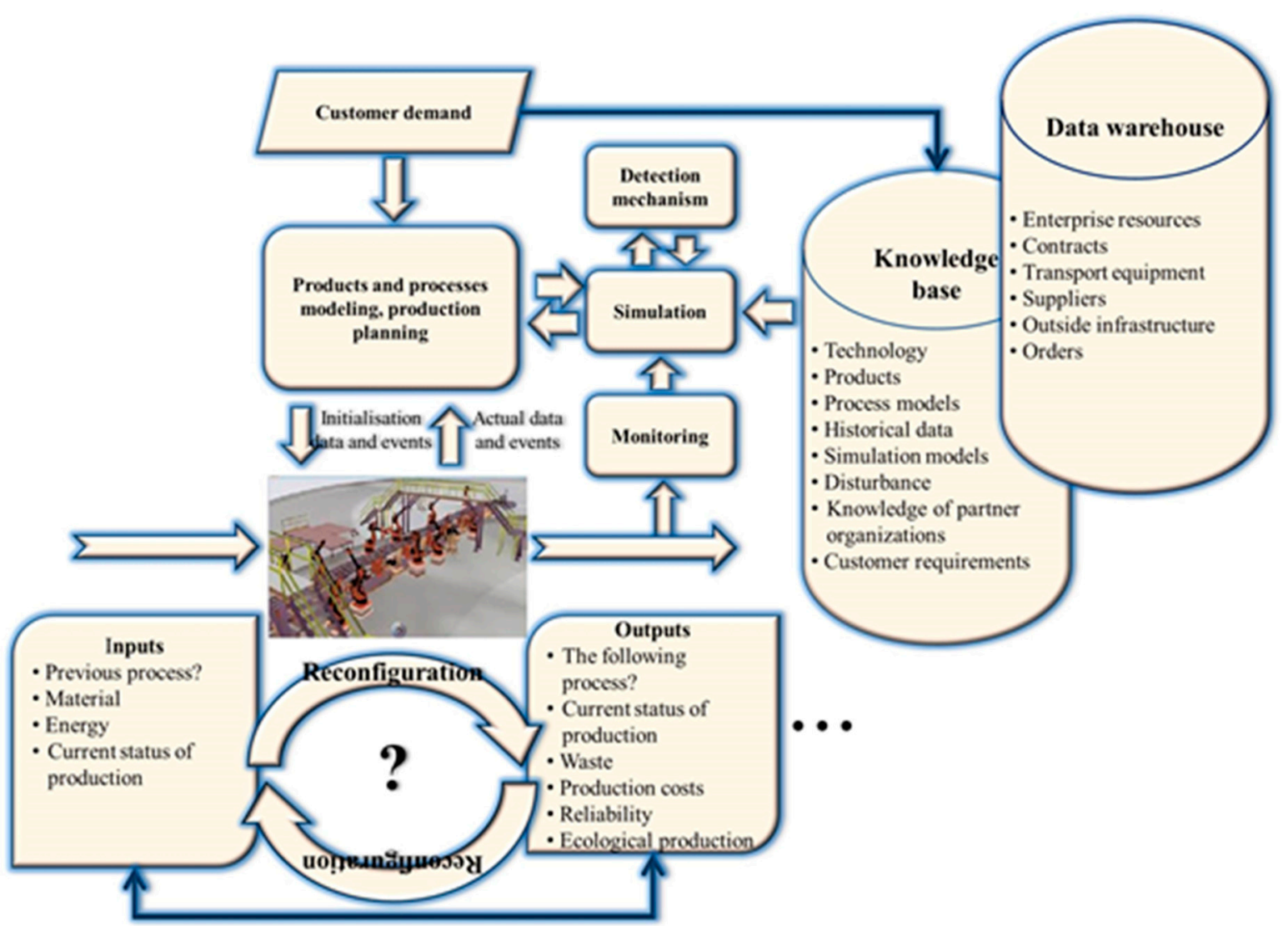

Figure 3. Intelligent learning mechanism of manufacturing resources.

Output parameters are monitored by the sensory disposition which converts the signals into actual data values and initializes activity of detection mechanism to detect abnormalities through a simulation model [35-37]. The increasing complexity of the system architecture may result in adverse effects on the autonomous control system tasks and system reliability.

Manufacturing and assembly systems must be equipped with reconfigurability, which provides for quick configuration of maintenance system and switches generating variants by switching generating tasks depending on the production need of a particular family of workpieces and subassemblied parts by adding or removing functional elements. Intelligent control mechanisms, as seen in Figure 4 should:

- ensure the transfer of data and information and then start to allocate the resources to activities can be performed;

- initiate the activities;

- coordinate the cooperation of production equipment during the execution of the activities;

- gather data and monitor the processes being executed;

- perform analytical procedures,

- evaluate actions and remedial activities;

- release the resources when the activity is completed;

- respond to problems and cooperate with the master system. 


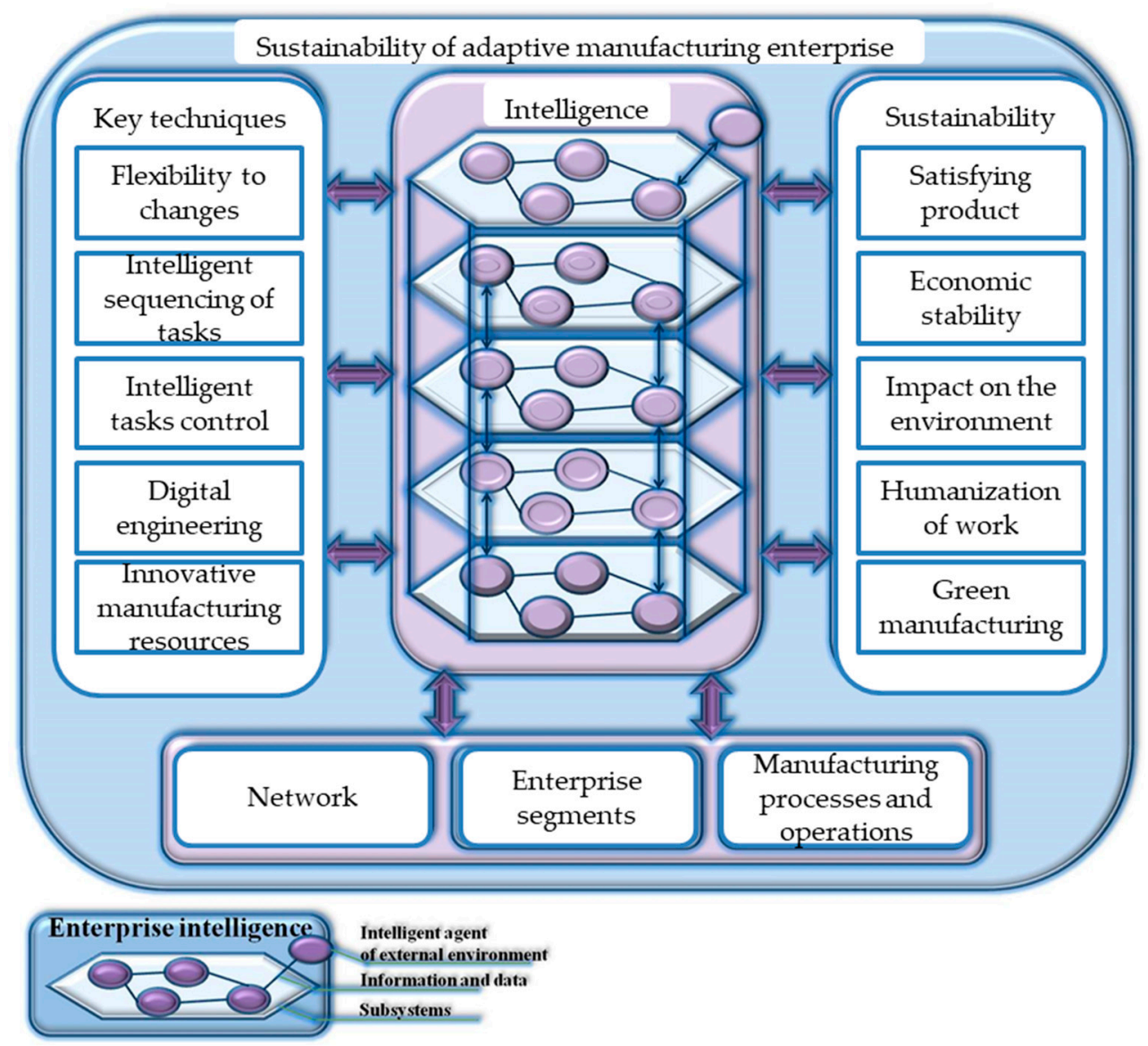

Figure 4. Sustainability of adaptive manufacturing enterprise.

The aim of the integrated control system is the sustainability of the production company in a competitive environment which includes the prerequisites for development.

The purpose of the reconfiguration is to change system functionality and ensure the scalability of the production capacity. Reconfiguration activities can independently add, delete, modify and convert machines (handling units) based on rapid response to changing requirements and the actual behavior of the system. The system with a given ability may increase the life of production and should offer a cost-beneficial solution in the long term.

\section{Design Method}

When addressing the issue, the authors used available scientific methods from the fields of industrial engineering, adaptive assembly, advanced segmentation, knowledge management [38], intelligent manufacturing systems, and other advanced industrial engineering methods.

The methodology of the innovative approach to product segmentation using the same operating times complements the tests carried out in laboratories at the Department of Industrial Engineering of University of Žilina, Slovakia. In order for the project to succeed, all three elements shall be met: finish the project within the set deadline, in the required quality and within the planned cost range. In various projects, individual elements of the Triple Constraint may differ in terms of scale of importance. In order for the project and its researchers to work effectively, technical equipment and the means to build a product segmentation model are needed along with the right conditions for experimental testing. The project methodology fit the workplace available at the Department of Industrial Engineering (Figure 5):

- product segmentation - assembly and control workstation (a), 
- virtual and augmented reality (b),

- $\quad$ interactive 3D design - cave (c),

- designing production and assembly systems (d),

- augmented reality mobile information system (e),

- collaborative robot (f).

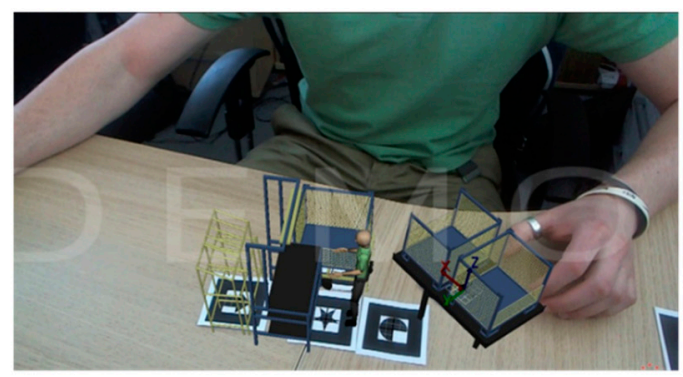

a) Examples of creating workspace variants

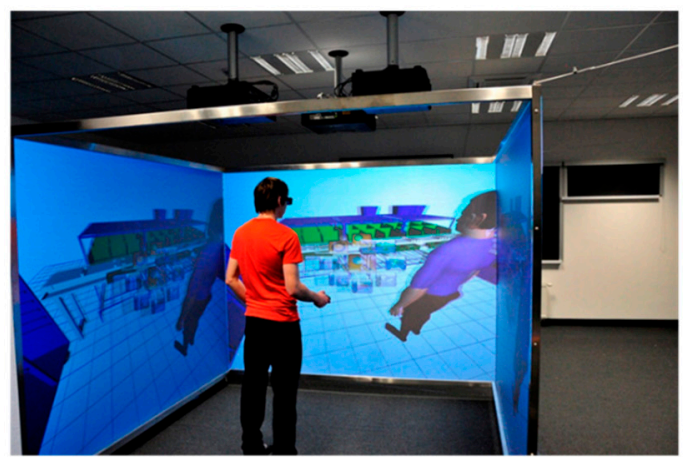

c) Virtual view of production layout in 3D

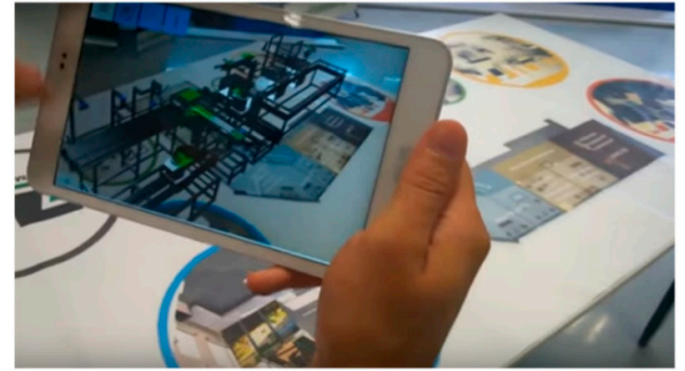

e) Augmented Reality Mobile Information System

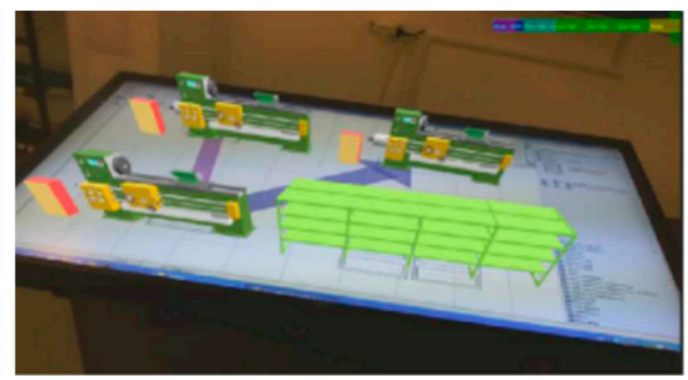

b) Connecting the augmented intelligence with a program to

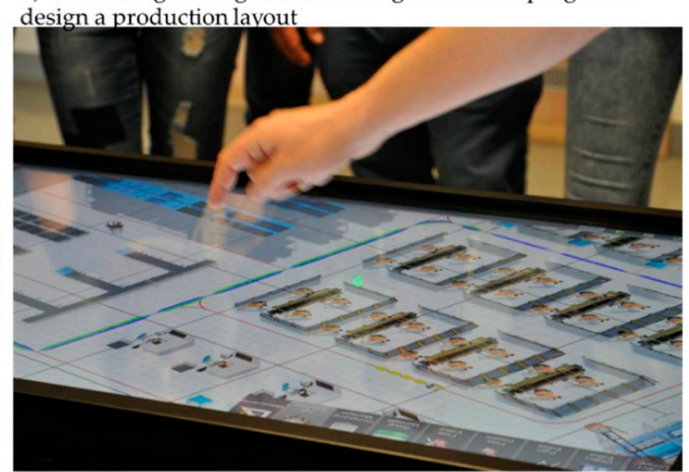

d) Example of work on projection table

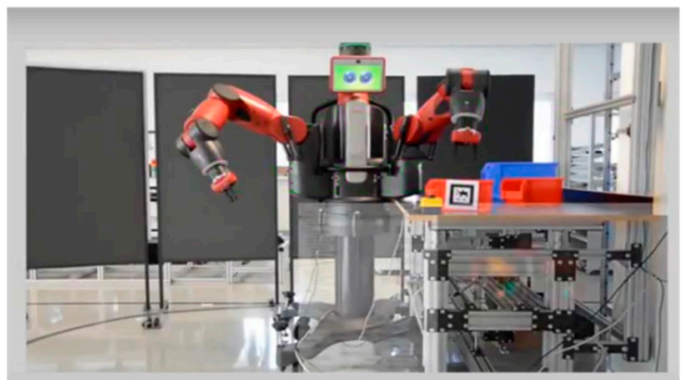

f) Collaborative robot

Figure 5. Laboratories - experimental testing.

Solution respecting the basic elements of Industry 4.0 meets the requirements of the interdisciplinary way of work which requires team organization and puts demands on the coordination of individual activities.

Advantages of segmented products according to the operating time of assembly operations:

1. Design the assembly line without queuing spots(reducing the line versatility factor $=$ reducing operating costs).

2. Reduction of work in progress and thereby accelerate process flow (removal of the moving bottleneck).

3. Reduce the production lead time (the increase of the value-added of the product compared to the time spent on the assembly line).

4. Increase in labor productivity (eliminate the waiting for the previous process to finish).

5. Improve the planning process (clear rules for identifying product families for assembly lines). 
Similarity coefficients are the fastest way to assess the similarity of two objects (for example, two products) based on the number of common or different characteristics.

There are several types of calculations:

Jaccard similarity coefficient:

$$
K p=\frac{a}{a+b+c}
$$

Sorenson similarity coefficient:

$$
K p=\frac{2 a}{2 a+b+c}
$$

The following applies:

$a$ - the number of common features in two objects,

$b$ - the number of features of object 1 that are not present in the object 2,

$c$ - the number of features of object 2 that are not present in the object 1 ,

$d$-number of characters that are not present in the object 1 nor in the object 2.

Segmentation of products and its methodology can be expressed in 5 points:

1. Build the matrix: Products - Technology (types - assembly operations).

2. Calculation of similarities (e.g., Jaccard coefficient) for each pair of products (for SLCA, CLCA and ALCA algorithms) or by an algorithm of a binary arrangement of components in the matrix (the ROC).

3. Adjustment similarity matrix according to the principles of the method chosen.

4. The gradual grouping of products into clusters (family or segments).

5. Graphical representation - dendogram or final matrix.

Segmentation is further used in an environment design assembly processes. The basic design phases of the new or to be improved assembly process are:

1. Analysis of the inputs ( $\mathrm{P}, \mathrm{Q}, \mathrm{R}, \mathrm{S}, \mathrm{T}$, segmentation of products, etc.).

2. Proposed structure assembly (manual, mechanical, etc.).

3. Draft the term structure (sequence of operations, performance standard installation).

4. Proposal of the spatial structure (layout distribution).

5. Target requirements.

6. Project implementation and deployment.

Note: P (product), Q (quantity), R (routing) - technological procedures, $\mathrm{S}$ (service) - technological equipment, $\mathrm{T}$ (time) - operating time.

\section{Case Study}

The very core of the scientific research is the issue of applying advanced segmentation that would allow products to be distributed in MTOs to families with a common sign of approximately equal operating times. This will increase the amount of available assembly lines in medium and large-sized enterprises without the need for large investments in the development and adaptation of the assembly process. There is no need to use complex planning methods that only partially eliminate the effects of external factors in MTO assemblies such as missing material, insufficient capacity of previous processes, product variants, or size of assembly batches. Utilization of the proposed segmentation approach for teaching purposes at the Department of Industrial Engineering is seen as a progressive approach to increase the overall efficiency of assembly processes. It is possible to adapt the number of segments created to a number of assembly lines. 
5.1. The Research Used Existing Models Of Products Segmentation and Their Impact on Performance Indicators such as LT, WIP, Direct Labor Efficiency

Process of sustainable product segmentation in customized assembly is shown in Figure 6. There are some important points to be mentioned:

1. The market requires large product diversification from manufacturers, short delivery dates and low prices. This is a clear demand for processes in terms of the need for low costs (high productivity), effective flows of information and material, or increased innovation.

2. The typical tasks of workshop planning in the custom assembly are: scheduling products and workers, determining optimal assembly lines and production capacities.

3. The assembly characteristics may include low repeatability of products, a high variety of products (product variants) and different working time (assembly time consumption, number of assembly operations and their different duration).

4. Products with a longer assembly time slow the previous assembly operation and the queues are formed. On the other hand, products that do not go through a particular operation may pass through the assembly line more quickly but are inhibited by products that must undergo more complex operations.

5. Difficult assembly process: the balancing of the assembly lines, assigning the staff on the individual operations and assembly lines and maintenance of the specified amount of the finished production may lead to a decrease in the labor productivity.

6. In an MTO strategy, the customer is ready to wait for the specified time before the order goes through the production processes, resulting in a product configured to meet customer's expectations. The price of the product is mostly influenced by the market, and manufacturers have to design their processes in a productive way so that they are based on the competitive production rate of the business. The shortening of the interim periods and the fulfilment of the promises regarding delivery times is crucial for these types of businesses.

7. Companies operating under ETOmanufacturing strategy focus on the storage of common materials, the orders placed are accepted by the development and engineering department based on specific requirements while maintaining efficient production. Therefore, customer's orders must go through the production process efficiently and directly without time-lag (wastes).

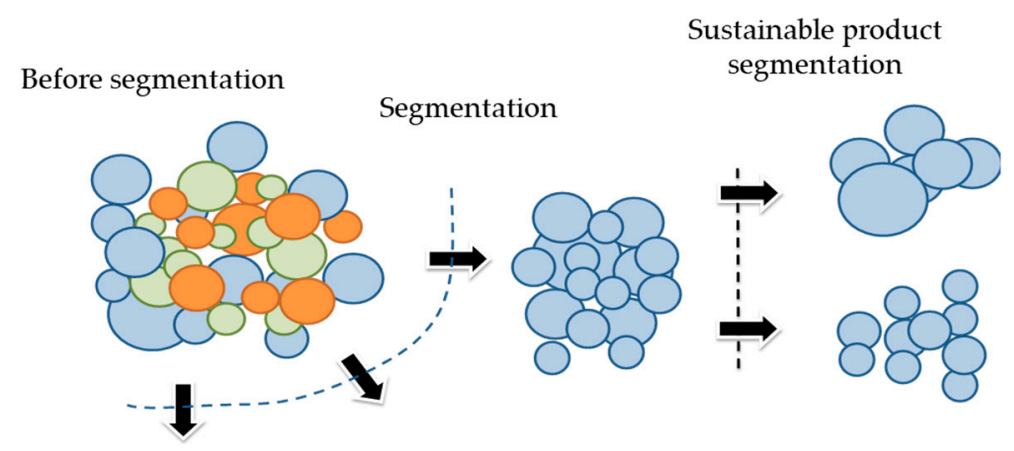

Figure 6. Sustainable product segmentation in customized assembly.

These findings provide the basis for the study. Unbalanced assembly lines, frequent rearrangement of staff at assembly lines and the unstable output from an assembly line are strategic tasks of order assembly planning. Insufficient task planning may result in the following:

1. imbalance in production capacities (free or too saturated capacity),

2. frequent and sudden shifting of workers between assembly posts (high flexibility reduces labor productivity), 
3. increasing WIP due to blocked capacities blocking or waiting for further follow-up operations.

4. frequent logistcs conflicts, problems with production capacities and production deadlines (in planning, it is important to accurately and timely arrange arrival of materials and release the production capacity at the same time);

5. increased need for the number of workers at the workplace (in the case of difficult, time-consuming orders, the consumption of workers is higher, assuming the same continuous production time, in the case of less demanding orders the need for workers is low).

\subsection{The Evaluation of Existing Approaches Used for Product Segmentation in Customized Assembly}

The table (Figure 7) shows an example of one product cluster from the set of several clusters that were segmented according to the occurrence of assembly operations. Products (A, C, D, ... ), which form one segment, represent a family of products with a common occurrence - the occurrence of assembly operations no. 1, 2, 4, 6, 7, 9 and 11, where:

\begin{tabular}{|c|c|c|c|c|c|c|c|c|c|c|}
\hline $\begin{array}{r}\text { Product } \\
\text { Operation }\end{array}$ & A & C & D & F & H & I & J & K & L & N \\
\hline AO1 & 0.7 & 0.0 & 0.4 & 1.2 & 0.8 & 0.9 & 1.2 & 1.2 & 0.8 & 0.7 \\
\hline AO2 & 1.5 & 1.7 & 1.4 & 2.1 & 2.2 & 1.3 & 1.0 & 2.1 & 2.2 & 2.0 \\
\hline AO4 & 2.0 & 1.0 & 2.2 & 2.5 & 1.5 & 1.5 & 1.7 & 2.5 & 1.5 & 2.0 \\
\hline AO6 & 5.7 & 2.5 & 3.7 & 6.8 & 3.1 & 4.2 & 3.1 & 7.3 & 2.5 & 5.7 \\
\hline AO7 & 0.0 & 0.3 & 0.2 & 0.3 & 0.3 & 0.0 & 1.1 & 0.2 & 0.3 & 0.2 \\
\hline AO9 & 1.4 & 1.6 & 1.1 & 1.5 & 1.7 & 1.6 & 1.4 & 1.5 & 1.6 & 1.1 \\
\hline A11 & 0.3 & 0.4 & 0.2 & 0.9 & 0.3 & 0.4 & 0,2 & 0.8 & 0.4 & 0.2 \\
\hline Sum & 11.6 & 7.5 & 9.2 & 15.3 & 9.1 & 9.9 & 9.6 & 15.6 & 9.3 & 11.9 \\
\hline
\end{tabular}

Figure 7. Products and their assembly operations.

AO1-AO11 - Assembly operations (Hrs).

A-N - Products.

Sum - Sum of time of assembly operation.

From the resulting segment we conclude the following:

1. This segment contains 10 products (A, C, D, F, H, I, J, K, L and N).

2. It associates 7 assembly operations (1, 2, 4, 6, 7, 9 and 11).

3. By assembling the assembly line or the production cell that contain those assembly operations, an assembly line for these product types will be established.

Figure 8 shows the differences in the individual operating times. Despite the fact that all these products are manufactural on one assembly line, their production time is different, and that can cause problems. 


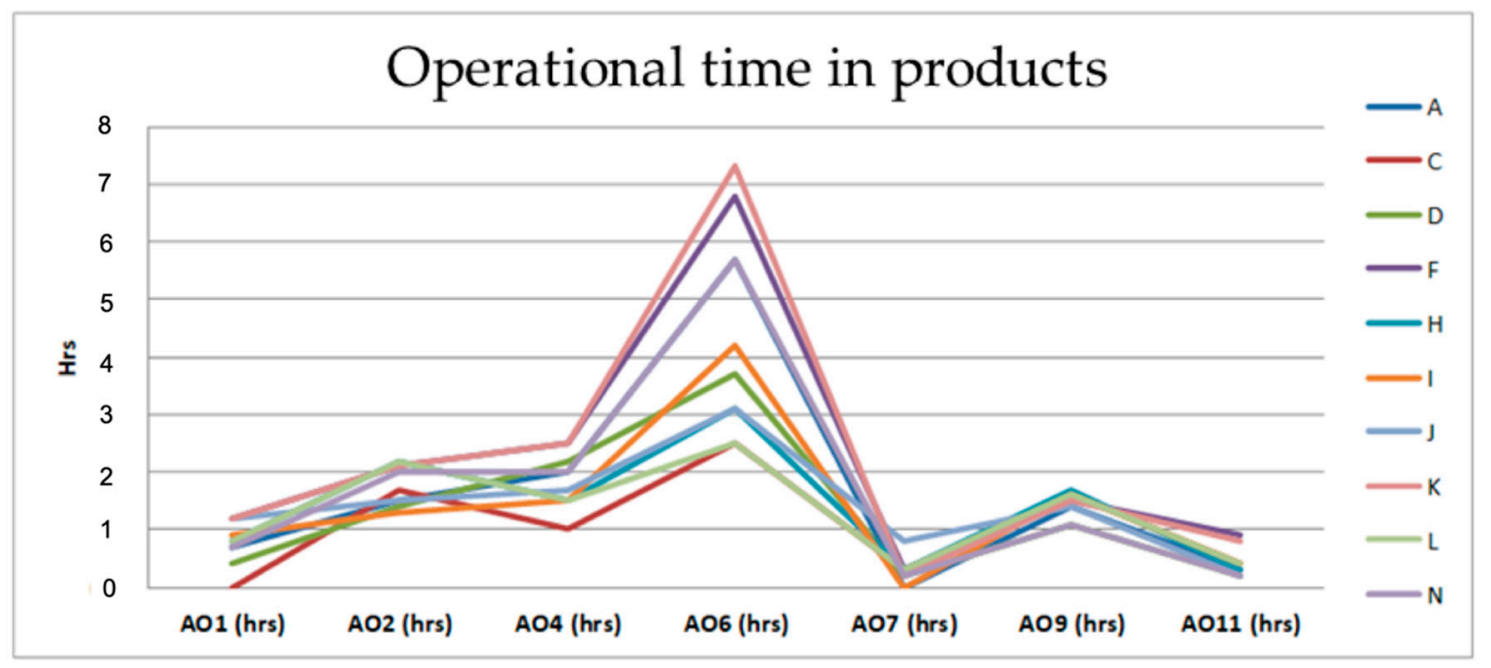

Figure 8. Operating times of cluster products.

This is an example of how the individual products (orders) can be segmented into a family of technologically similar products that can be assembled in a production cell, an autonomous production cell or assembly line. From a segmentation point of view, the process is completed; the segment is identified and represents the input information for other planning processes or designing manufacturing systems. The problem arises when we look at the lengths of the operating times.

Products with a shorter total production time go through the assembly line faster than products with longer production times. This will be true on condition that only product with short production time would be assembled on the assembly line. Products with a longer assembly time take longer to be assembled.

This study outlines the method that does not take into account the complex planning methods which may help in the planning of similar products. Furthermore, the new method allows releasing the product from the selected assembly lines at any time.

This method takes into account the arrival of important materials at the beginning of the assembly. It should be especially noted that companies (making custom-made products) do not keep slow-moving material at the warehouse, but they get the material before the start of the assembly process.

5.3. The Theoretical Design of New Innovative Approach to Products Segmentation for Creating the Intelligent Adaptive System

Since different companies produce different products at different production times, it is necessary to find such an approach that will be universal for all types of custom assembly processes.

We outline a simple procedure of how to segment products according to operational times. The results are shown in Figure 9. 


\begin{tabular}{|c|c|c|c|c|c|c|c|c|c|c|c|c|c|c|c|}
\hline Product & \multirow[t]{2}{*}{$\mathbf{A}$} & \multirow[t]{2}{*}{$\mathrm{C}$} & \multirow[t]{2}{*}{ D } & \multirow[t]{2}{*}{$F$} & \multirow[t]{2}{*}{$\mathbf{H}$} & \multirow[t]{2}{*}{ I } & \multirow[t]{2}{*}{$\mathbf{J}$} & \multirow[t]{2}{*}{ K } & \multirow[t]{2}{*}{$\mathbf{L}$} & \multirow[t]{2}{*}{$\mathbf{N}$} & \multirow[t]{2}{*}{ Max } & \multirow[t]{2}{*}{ Min } & \multirow[t]{2}{*}{ Avg } & \multirow[t]{2}{*}{ Diff } & \multirow[t]{2}{*}{ Prio } \\
\hline $\begin{array}{c}\text { Operatio } \\
\mathbf{n}\end{array}$ & & & & & & & & & & & & & & & \\
\hline AO1 & 0.7 & 0.0 & 0.4 & 1.2 & 0.8 & 0.9 & 1.2 & 1.2 & 0.8 & 0.7 & 1.2 & 0.0 & 0.6 & 1.2 & 1 \\
\hline $\mathrm{AO} 2$ & 1.5 & 1.7 & 1.4 & 2.1 & 2.2 & 1.3 & 1.0 & 2.1 & 2.2 & 2.0 & 2.2 & 1.3 & 1.8 & 0.9 & 0 \\
\hline $\mathrm{AO} 4$ & 2.0 & 1.0 & 2.2 & 2.5 & 1.5 & 1.5 & 1.7 & 2.5 & 1.5 & 2.0 & 2.5 & 1.0 & 1.8 & 1.5 & 2 \\
\hline AO6 & 5.7 & 2.5 & 3.7 & 6.8 & 3.1 & 4.2 & 3.1 & 7.3 & 2.5 & 5.7 & 7.3 & 2.5 & 4.9 & 4.8 & 3 \\
\hline AO7 & 0.0 & 0.3 & 0.2 & 0.3 & 0.3 & 0.0 & 1.1 & 0.2 & 0.3 & 0.2 & 0.8 & 0.0 & 0.4 & 0.8 & 0 \\
\hline AO9 & 1.4 & 1.6 & 1.1 & 1.5 & 1.7 & 1.6 & 1.4 & 1.5 & 1.6 & 1.1 & 1.7 & 1.1 & 1.4 & 0.6 & 0 \\
\hline A11 & 0.3 & 0.4 & 0.2 & 0.9 & 0.3 & 0.4 & 0.2 & 0.8 & 0.4 & 0.2 & 0.9 & 0.2 & 0.6 & 0.7 & 0 \\
\hline
\end{tabular}

Figure 9. Table with auxiliary calculations.

In the beginning, it is necessary to determine the maximum and minimum times of assembly operations for individual products (Max, Min). These values will serve to calculate differences between the shortest and longest operating times.

In the second step, it is necessary to specify the average operating times (AVG) of the assembly operations and the difference (Diff) between Max and Min.

The third step is to determine the number of segmentation steps. The number of steps depends on several factors:

1. Operating time. It is different when the operation time takes $10 \mathrm{~h}$ and the difference in operations is $1 \mathrm{~h}(10 \%)$ and when the operation takes $1 \mathrm{~h}$ and the difference in operations is $0.6 \mathrm{~h}$ (representing $60 \%)$.

2. Differences between Max and Min. How significant they are (such as high AVG).

3. How high is the difference value (Diff). The higher the value (the difference between Max and Min) the higher is the step number.

4. Types of production or assembly lines. Which differences in operating times can be processed without lowering the productivity or significantly increasing the WIP.

Where:

Max, Min - Maximum or minimum value of the duration of operation.

Sum - Sum of time of assembly operation.

Avg - Average between the max and min.

Diff-Difference between the max and min.

Prio - Priority.

If the assembly line is able to absorb $1 \mathrm{~h}$ difference, assign it the step 0 . The difference of $1.2 \mathrm{~h}$ should be placed under the step 1 . Furthermore, the differences of 1.5 should be placed under step 2 (priority 2). Finally, the difference $4.8 \mathrm{~h}$ shall be placed under the step 3 (priority 3). It is shown on the right (Figure 9).

With the step no. 0 , we do not segment0. The ranking doe not go from the highest number to the smallest. The actual segmentation starts with the assembly operation in step 1 and continues with stp 2 and step 3. Let's now focus on the table (Figure 10):

1. The table can be divided according to the assembly operation no. 6 (segmentation step 3) because it has the greatest differences in the length of the operating times.

2. In segment no. 1 there are products: K, F, A, N. (approximately similar operating times)

3. In segment no. 2 there are products: I, D, J, H, L, C. (approximately similar operating times) 


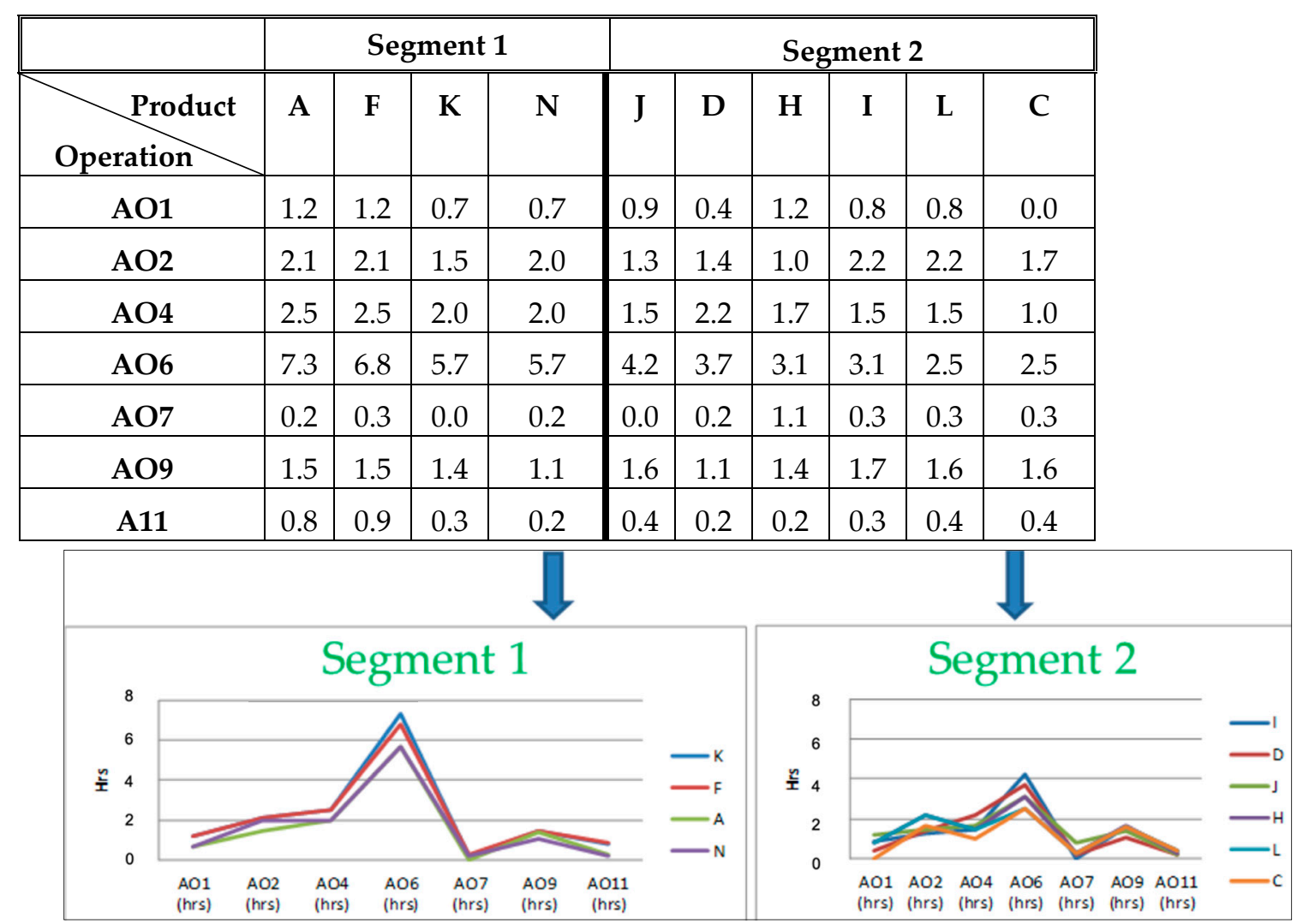

Figure 10. Final table after segmentation according to operating times with chart of length of assembly operations.

The outcomes of the research are:

1. the design of product identification methods for the purpose of determining the assembly line segment and planning for assembly,

2. the design of assembly process characteristics in which the innovative approach of products segmentation is applied,

3. the proposal for draft decision criteria for the analyst and administrator of the knowledge base of the maintenance system.

\subsection{Validation of the Theoretical Design in the Company}

Emerson Network Power is the world's leading provider of critical infrastructure technologies and lifecycle services for information and communications technology systems. With an expansive portfolio of intelligent, rapidly deployable hardware and software solutions for power, thermal and infrastructure management, Emerson Network Power provides efficient, highly-available networks [39].

Ensure all customer requirements have resulted in the high variability of products. The assembly line must be designed to produce products with a wide variation of operating times and a number of assembly operations. The products' operating time varies between $8.0 \mathrm{~h}$ to $23.0 \mathrm{~h}$ during which they undergo 5 to 8 assembly operations. In the production, there are three-segmented lines where the planning system could order any products after advance segmentation because each line is managed for a certain family of products with comparable operating times and assembly operations.

What is even more exceptional is this: these segmented products could order planning system anytime the material needed is available. We also outline an example of products before segmentation by operational time (Figure 11). 


\begin{tabular}{|l|l|l|l|l|l|}
\hline Description & Pick Date & Finish WO & Order Qty & Total hours & Hours per unit \\
\hline S0FUA/1/21/03/0/1 & 25.11 .2016 & 23.11 .2016 & 6 & 45.0 & 7.5 \\
\hline S1DOA/1/01/V/B/0 & 28.11 .2016 & 23.11 .2016 & 1 & 9.4 & 9.4 \\
\hline S15OC/2/00/0/B/0/2 & 24.11 .2016 & 24.11 .2016 & 1 & 9.3 & 9.3 \\
\hline S0FUA/1/21/0/3/0/1 & 25.11 .2016 & 24.11 .2016 & 6 & 45.0 & 7.5 \\
\hline PX015DA/1/3/7/S/3 & 28.11 .2016 & 24.11 .2016 & 1 & 8.0 & 8.0 \\
\hline S18OC/1/00/0/B/0/2 & 25.11 .2016 & 25.11 .2016 & 2 & 15.6 & 7.8 \\
\hline SOHDA/1/00/0/C/0 & 01.12 .2016 & 25.11 .2016 & 1 & 9.9 & 9.9 \\
\hline PX015DA/1/3/7/S/D & 28.11 .2016 & 25.11 .2016 & 1 & 8.2 & 8.2 \\
\hline S1GUA/2/01/V/B/0 & 29.11 .2016 & 28.11 .2016 & 2 & 17.9 & 9.0 \\
\hline S1AOA/1/00/0/A/0 & 05.12 .2016 & 29.11 .2016 & 2 & 19.4 & 9.7 \\
\hline S2HDA/1/01/0/C/0 & 01.12 .2016 & 25.11 .2016 & 1 & 8.0 & 8.0 \\
\hline PX025DA/1/4/7/S/D & 28.11 .2016 & 25.11 .2016 & 1 & 9.3 & 9.3 \\
\hline S1GA/2/01/C/B/0/0 & 29.11 .2016 & 28.11 .2016 & 2 & 15.6 & 7.8 \\
\hline
\end{tabular}

Figure 11. Variance production times in products before segmentation by operational times.

Where:

Finish WO - Finish of work order,

Order Qty - Order quantity (number of pieces).

This is an extract from the previous table but this time, it underwent segmentation by operational time (Figure 12). The products that had a significant difference in operational time were moved to another cluster after segmentation by operational times was carried out.

\begin{tabular}{|l|l|l|c|c|c|}
\hline Description & Pick Date & Finish WO & Order Qty & Total hours & Hours per unit \\
\hline S0FKA/1/21/V/D/G & 24.11 .2016 & 23.11 .2016 & 1 & 12.7 & 12.7 \\
\hline S0FUA/1/21/0/3/0/1 & 25.11 .2016 & 23.11 .2016 & 6 & 45.0 & 7.5 \\
\hline S0HPW/1/01/V/D/G & 01.12 .2016 & 23.11 .2016 & 1 & 17.5 & 17.5 \\
\hline S1DOA/1/01/V/B/0 & 28.11 .2016 & 23.11 .2016 & 1 & 9.4 & 9.4 \\
\hline S15OC/2/00/0/B/0/2 & 24.11 .2016 & 24.11 .2016 & 1 & 9.3 & 9.3 \\
\hline S29DC/1/00/0/D/0/2 & 01.12 .2016 & 24.11 .2016 & 1 & 10.8 & 10.8 \\
\hline S0FUA/1/21/0/3/0/1 & 25.11 .2016 & 24.11 .2016 & 6 & 45.0 & 7.5 \\
\hline PX015DA/1/3/7/S/3 & 28.11 .2016 & 24.11 .2016 & 1 & 8.0 & 8.0 \\
\hline PX015DD/1/3/6/S/B & 29.11 .2016 & 24.11 .2016 & 1 & 11.6 & 11.6 \\
\hline S18OC/1/00/0/B/0/2 & 25.11 .2016 & 25.11 .2016 & 2 & 15.6 & 7.8 \\
\hline S0HDA/1/00/0/C/0 & 01.12 .2016 & 25.11 .2016 & 1 & 9.9 & 9.9 \\
\hline PX031HA/L/T/S/0/3 & 29.11 .2016 & 25.11 .2016 & 4 & 53.4 & 13.4 \\
\hline PX015KW/1/3/6/S/D & 29.11 .2016 & 25.11 .2016 & 1 & 13.8 & 13.8 \\
\hline PX015DA/1/3/7/S/D & 28.11 .2016 & 25.11 .2016 & 1 & 8.2 & 8.2 \\
\hline S0HKA/1/01/V/D/G & 24.11 .2016 & 24.11 .2016 & 1 & 12.2 & 12.2 \\
\hline S1GUA/2/01/V/B/0 & 29.11 .2016 & 28.11 .2016 & 2 & 17.9 & 9.0 \\
\hline S1GDA/1/01/V/D/0 & 29.11 .2016 & 28.11 .2016 & 2 & 21.7 & 10.9 \\
\hline PX031HA/L/T/S/0/3 & 29.11 .2016 & 28.11 .2016 & 4 & 53.4 & 13.4 \\
\hline S0FKA/2/21/V/B/G & 06.12 .2016 & 29.11 .2016 & 1 & 12.7 & 12.7 \\
\hline S0FKA/2/21/V/B/G & 06.12 .2016 & 29.11 .2016 & 1 & 12.7 & 12.7 \\
\hline S0FKA/2/21/V/B/G & 06.12 .2016 & 29.11 .2016 & 1 & 11.7 & 11.7 \\
\hline S1AOA/1/00/0/A/0 & 05.12 .2016 & 29.11 .2016 & 2 & 19.4 & 9.7 \\
\hline
\end{tabular}

Figure 12. Variance production times in products after segmentation by operational times. 


\section{Discussion and Conclusion}

Results of the proposal of technical and economic assessment and the return of investment of application model are:

1. thanks to the extended segmentation, products can be distributed in MTOs to families of products with a common value - approximately same operating times. This will increase assembly speed in already medium to large companies without the need for big investments into the development or the need to adapt the assembly process products,

2. there is no need to use complex planning methods that only partially eliminate the effects of external factors in MTO assemblies such as missing material, insufficient capacity of previous processes, product variants, or size of assembly batches,

3. it is possible to adapt the number of segments created to a number of assemblies (existing or designed) lines.

This allows the company:

1. start with the assembly of any product at any time the material is available (simple planning rules - typical for order production), improve the planning process = focusing on the due date (typical for MTO and ETO environment),

2. utilize assembly lines without queues (all products in the segment have almost the same operational time of assembly operations),

3. reducing Work in Progress (acceleration of the flow without waiting),

4. shortening of assembly time (lead time),

5. increasing labor efficiency.

A summary of the steps of a new segmentation approach is shown in Figure 13. There is a step by step manual showing how to perform pre-calculation and sorting (segmentation) using specified steps, as explained above. Since we talk about MTO and ETO, which are not supposed to bind the slow-moving components in the warehouse, the arrival of materials is very important for the start of assembly. This method allows the product to be programmed at any time (after arrival) into the flow of the assembly line without complicated planning calculations (alignment), thus greatly improving the planning and alignment process. Such product allocation allows for the use of a smart assembly line without waiting and complicated alignment process, which means less spatial layout.

This results in the reduction of WIP (work in progress) and a shorter assembly time or LT (lead time). Due to the variation and reproducibility of the products and the different assembly time of individual products, there are several models of assembly processes. The development of industrial enterprises is currently makes use of new knowledge gained from various sources of information, globalization and the increasing possibilities provided by modern means of computer technology. All this is happening thanks to the development of knowledge management, new discoveries and innovations, as well as increased pressures from the external environment to meet customers' expectations. The customer is currently not satisfied with the standard product, which can also compete with it. 


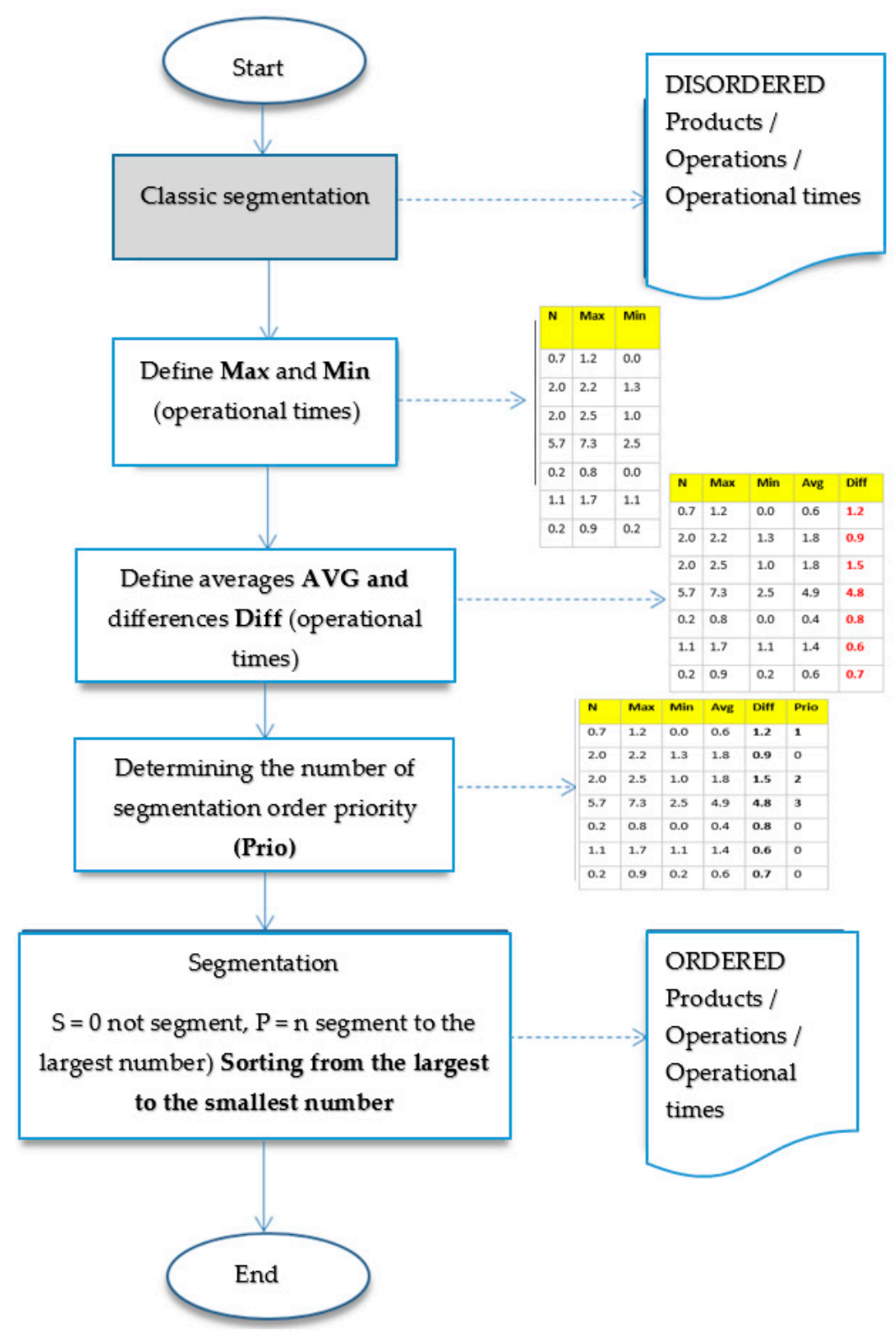

Figure 13. Flow chart of segmentation according to operating times.

Increasingly, the customer is drawn into the development, design, or direct configuration of products to meet his diversification requirements. This trend still has the same foundation and aims at being profitable and competitive in the market segment on which the company currently operates. Finding new trends, options or processes to maintain or gain these benefits is an ongoing struggle that moves companies forward to the previously unachievable goals. The ability to achieve low lead times, low production costs, and high productivity in highly varied manufacturing (assembly) opens a new space to meet customer expectations, increase customization of products, and stability of businesses on the market.

Further research into new customized segments can be divided into 3 main areas:

1. Software integration of the new segmentation approach - this area includes the research topics on the digital business. Using a new segmentation approach in SW designing such as Tecnomatix (Siemens PLM Software), VisTable - interactive design, or Delmia software modules (Dassault Systems) working with virtual reality. 
2. Possibilities of assembly optimization from segmentation point of view - new technological processes and efficient devices can reduce the optimization of assembly: the aim of this research section is to optimize installation in terms of utilization of production capacities, product planning and structure.

3. The follow-up to the new segmentation approach and simulation of the assembly process - the possibility of writing follow-up bachelor and diploma theses and professional studies.

This study can be used as a basis for further studies and utilization of the proposed segmentation approach for teaching purposes at the Department of Industrial Engineering as a material for increasing the overall efficiency of assembly processes within the subject Production Systems Design and Operational Management. It is a suitable tool for further research and application in the software form of integrated enterprise systems. Future research is therefore needed to identify and test the the options that are adaptive and robust enough to yield positive results in the future. On the physical level, the manufacturing and assembly systems (RMS and RAS) have to be reconfigurable and the factory with its technical infrastructure including building should be transformable (TRF). Major modules at the theoretical level are necessary to operate a factory and must also be changeable in order to support the changes at the practical levels. This calls for a process planning system that is able to react to changes in the products design or the physical manufacturing resources. Thus, the system is called reconfigurable process planning (RPP).

Author Contributions: Conceptualization, V.B., B.M. and R.L.; methodology, R.L.; software, R.L.; validation, M.K. and L.D.; formal analysis, V.B.; investigation, B.M.; resources, M.K.; data curation, R.L.; writing-original draft preparation, V.B.; writing-review and editing, V.B. and R.L.; visualization, V.B.; supervision, B.M.; project administration, V.B.; funding acquisition, B.M., M.K. and L.D." All authors read and approved the final manuscript.

Funding: This research was funded by APVV-16-0488.

Acknowledgments: This work was supported by the Slovak Research and Development Agency under the contract No. APVV-16-0488.

Conflicts of Interest: The authors declare no conflict of interest.

\section{References}

1. Avarez, R.; Calvo, R.; Peña, M.M.; Domingo, R. Redesigning an assembly line through lean manufacturing tools. Int. J. Adv. Manuf. Technol. 2009, 43, 949. [CrossRef]

2. Faber, M.; Bützler, J.; Schlick, C.M. Human-robot cooperation in future production systems: Analysis of requirements for designing an ergonomic work system. Procedia Manuf. 2015, 3, 510-517. [CrossRef]

3. Haluska, M.; Gregor, M. Concept of the system for design and optimization of configurations in new generation of manufacturing systems. Int. J. Manag. Soc. Sci. Res. Rev. 2016, 1, 181-184.

4. Oztemel, E.; Gursev, S. Literature review of Industry 4.0 and related technologies. J. Intell. Manuf. 2018, $29,1-56$. [CrossRef]

5. Scheer, S. Industry 4.0: Wie Sehen Produktionsprozesse im Jahr 2020; E-book; AWS-Institute for Digitized Products and Processes: Saarbrucken, Germany, 2013.

6. Scheuermann, C.; Verclas, S.; Bruegge, B. Agile factory-An example of an industry 4.0 manufacturing process, cyber-physical systems. In Proceedings of the IEEE 3rd International Conference on Networks, and Applications (CPSNA), Hong Kong, China, 19-21 August 2015; pp. 43-47.

7. Abdi, M.R.; Labib, A.W. Grouping and selecting products: The design key of reconfigurable manufacturing systems (RMSs). Int. J. Prod. Res. 2004, 42, 521-546. [CrossRef]

8. McAuley, J. Machine grouping for efficient production. Prod. Eng. 1972, 51, 53-57. [CrossRef]

9. Galan, R.; Racero, J.; Eguia, I.; Garcia, J.M. A systematic approach for product families formation in Reconfigurable Manufacturing Systems. Robot. Comput. Integr. Manuf. 2007, 23, 489-502. [CrossRef]

10. Seifoddini, H.; Wolfe, P.M. Application of the similarity coefficient method in group technology. IIE Trans. 1986, 18, 271-277. [CrossRef]

11. Goyal, K.K.; Jain, P.; Jain, M. A comprehensive approach to operation sequence similarity based part family formation in the reconfigurable manufacturing system. Int. J. Prod. Res. 2013, 51, 1762-1776. [CrossRef] 
12. Rakesh, K.; Jain, P.; Mehta, N. A framework for simultaneous recognition of part families and operation groups for driving a reconfigurable manufacturing system. Adv. Prod. Eng. Manag. J. 2010, 5, 45-58.

13. Lee, J.; Kao, H.-A.; Yang, S. Service innovation and smart analytics for industry 4.0 and big data environment. Procedia CIRP 2014, 16, 3-8. [CrossRef]

14. Neslušan, M.; Mičieta, B.; Mičietová, A.; Čilliková, M.; Mrkvica, I. Detection of tool breakage during hard turning through acoustic emission at low removal rates. Measurement 2015, 70, 1-13. [CrossRef]

15. Leitao, P.; Marik, V.; Vrba, P. Past, Present, and Future of Industrial Agent Applications. IEEE Trans. Ind. Inform. 2013, 9, 2360-2372. [CrossRef]

16. Gašo, M.; Krajčovič, M.; Dulina, L'.; Grznár, P.; Vaculík, J. Methodology of Creating and Sustainable Applying of Stereoscopic Recording in the Industrial Engineering Sector. Sustainability 2019, 11, 2194. [CrossRef]

17. Jain, A.; Jain, P.K.; Chan, F.T.S.; Singh, S. A review on manufacturing flexibility. Int. J. Prod. Res. 2013, 51, 5946-5970. [CrossRef]

18. Micieta, B.; Edl, M.; Krajcovic, M.; Dulina, L.; Bubenik, P.; Durica, L.; Binasova, V. Delegate MASs for coordination and control of one-directional AGV systems: A proof-of-concept. Int. J. Adv. Manuf. Technol. 2018, 94, 415-431. [CrossRef]

19. Salvendy, G. Handbook of Industrial Engineering; John Wiley \& Sons, Inc.: Toronto, ON, Canada, 2001. [CrossRef]

20. Tseng, M.M.; Hu, S.J. Mass customization. In CIRP Encyclopedia of Production Engngineering; Springer: Berlin, Germany, 2014; pp. 836-843.

21. Voss, C.; Blackmon, K. Differences in manufacturing strategy decisions between Japanese and Western manufacturing plants: The role of strategic time orientation. J. Oper. Manag. 1998, 16, 147-158. [CrossRef]

22. Geyer, A. The challenge of sustainable manufacturing-Four scenarios 2015-2020. Innov. Organ. Manag. 2014, 6, 331-343.

23. Moon, I.; Logendran, R.; Lee, J. Integrated assembly line balancing with resource restrictions. Int. J. Prod. Res. 2009, 47, 5525-5541. [CrossRef]

24. Micieta, B.; Markovic, J.; Binasova, V. Advances in sustainable energy efficient manufacturing system. MM Sci. J. 2016. [CrossRef]

25. Lerher, T.; Edl, M.; Rosi, B. Energy efficiency model for the mini-load automated storage and retrieval systems. Int. J. Adv. Manuf. Technol. 2014, 70, 97-115. [CrossRef]

26. Micieta, B.; Lieskovsky, R.; Binasova, V. Design of product segmentation in assembly line. MM Sci. J. 2016, 1297-1303. [CrossRef]

27. Hui, C.; Yuan, L.; Kai-fu, Z. Efficient method of assembly sequence planning based on GAAA and optimizing by assembly path feedback for complex product. Int. J. Adv. Manuf. Technol. 2009, 42, 1205. [CrossRef]

28. Womack, J.P.; Jones, D.T. Lean Thinking: Banish Waste and Create Wealth in Your Corporation; Simon \& Schuster UK Ltd.: London, UK, 2003.

29. Krajčovič, M.; Hančinský, V.; Dulina, L’.; Grznár, P.; Gašo, M.; Vaculík, J. Parameter Setting for a Genetic Algorithm Layout Planner as a Toll of Sustainable Manufacturing. Sustainability 2019, 11, 2083. [CrossRef]

30. Levinson, W.A. Henry Ford's Lean Vision: Enduring Principles from the First Ford Motor Plant; Productivity Press: New York, NY, USA, 2002.

31. Grznár, P.; Gregor, M.; Mozol, Š.; Krajčovič, M.; Dulina, L'; Gašo, M.; Major, M. A System to Determine the Optimal Work-in-Progress Inventory Stored in Interoperation Manufacturing Buffers. Sustainability 2019, 11, 3949. [CrossRef]

32. El Maraghy, H. Changing and Evolving Products and Systems-Models and Enablers, Changeable and Reconfigurable Manufacturing; Springer: London, UK, 2009; pp. 25-45.

33. Li, S.; Wang, H.; Hu, S.J. Assembly system configuration design for a product family. In Proceedings of the 41st North American Manufacturing Research Conference 2013 (NAMRC 2013), Madison, WI, USA, 10-14 June 2013.

34. CEC-Commission of the European Communities. A Sustainable Europe for a Better World: A European Union Strategy for Sustainable Development; Communication from the Commission: Brussels, Belgium, 2001; p. 264.

35. Vavrík, V.; Gregor, M.; Grznár, P. Computer simulation as a tool for the optimization of logistics using automated guided vehicles. Procedia Eng. 2017, 192, 923-928. [CrossRef]

36. Gregor, M.; Herčko, J.; Grznár, P. The factory of the future production system research. In Proceedings of the 2015 21st International Conference on Automation and Computing (ICAC), Glasgow, UK, 11-12 September 2015; pp. 1-6. 
37. Sásik, R.; Haluška, M.; Madaj, R.; Gregor, M.; Grznár, P. Development of the assembly set for the logistic transport solution. In The Latest Methods of Construction Design; Springer: Cham, Switzerland, 2016; pp. 81-86.

38. Seemann, P. Upcoming global method of team coaching in increasing employee motivation. In Proceedings of the 16th International Scientific Conference on Globalization and Its Socio-Economic Consequences, Rajecke Teplice, Slovakia, 5-6 October 2016.

39. Emerson. Emerson Network Power. Nove Mesto nad Vahom. Available online: https://www.emerson.com/ sk-sk (accessed on 6 October 2019). 